\title{
Features of DiGeorge syndrome and CHARGE association in five patients
}

Pascale de Lonlay-Debeney, Valérie Cormier-Daire, Jeanne Amiel, Véronique Abadie, Sylvie Odent, Alain Paupe, Sophie Couderc, Anne-Lorraine Tellier, Damien Bonnet, Marguerite Prieur, Michel Vekemans, Arnold Munnich, Stanislas Lyonnet

\begin{abstract}
We report on five patients presenting with features of two congenital disorders, DiGeorge syndrome (DGS) and CHARGE association. CHARGE association is usually sporadic and its origin is as yet unknown. Conversely, more than $90 \%$ of DGS patients are monosomic for the 22q11.2 chromosomal region. In each of the five patients, both cytogenetic and molecular analysis for the 22 q11.2 region were normal. In view of the broad clinical spectrum and the likely genetic heterogeneity of both disorders, these cases are consistent with the extended phenotype of either DGS without 22q11.2 deletion or CHARGE association, especially as several features of CHARGE association have been reported in rare patients with 22q11.2 deletion associated phenotypes. On the other hand, these could be novel cases of an independent association involving a complex defect of neural crest cells originating from the pharyngeal pouches.
\end{abstract}

$(\Im$ Med Genet 1997;34:986-989)

Keywords: DiGeorge syndrome; CHARGE association; chromosome 22q11.2; chromosome 10p

Pédiatrie, Hôpital

Necker-Enfants

Malades, 149 rue de

Sèvres, 75743 Paris

Cedex 15, France

V Abadie

D Bonnet

Service de Pédiatrie Générale, Centre Hospitalier

Intercommunal Léon

Touhladjian, rue

Champ Gaillard, 78300

Poissy, France

A Paupe

$S$ Couderc

Service de Pédiatrie et de Génétique Médicale, Centre Hospitalier Régional et Universitaire, 2 rue Henri Le Guilloux, 35000 Rennes, France $S$ Odent

Correspondence to: Dr Lyonnet.

Received 17 April 1997 Revised version accepted for publication 27 July 1997

DiGeorge syndrome (DGS) is a frequent developmental disorder involving hypoplasia or aplasia of the thymus and parathyroids, facial dysmorphic features, and conotruncal cardiac malformation. ${ }^{1-7}$ The vast majority of DGS patients are monosomic for the 22q11.2 chromosomal region..$^{8-13}$ On the other hand, CHARGE association is a rare multiple congenital malformation characterised by coloboma, heart malformation, choanal atresia, retardation of physical and mental development, genital hypoplasia, and ear anomalies/deafness. ${ }^{14-17}$ While CHARGE association is usually a sporadic event of unknown origin, rare familial cases or chromosomal anomalies have been reported. ${ }^{14}{ }^{15}$ 18-21 However, the vast majority of CHARGE patients do not have a 22q11.2 deletion (Theophile et al, submitted). Here, we report on five patients with characteristic anomalies of both DGS and CHARGE association. In view of the broad clinical spectrum and the genetic heterogeneity of both disorders, these cases could be consistent with the extended phenotype of either DGS or CHARGE association without a 22q11.2 deletion. Conversely, they

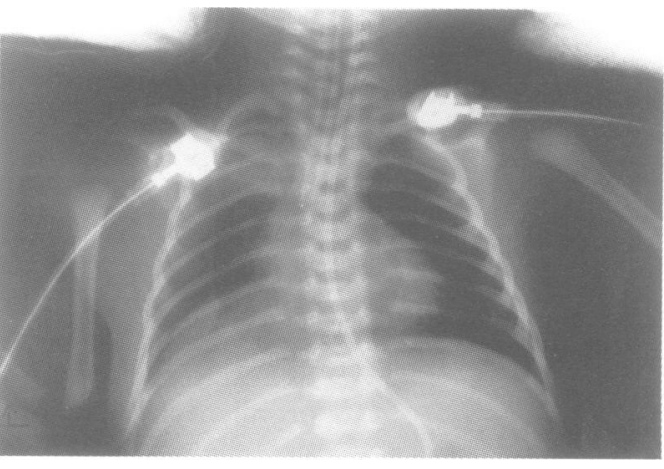

Figure 1 Thoracic $x$ ray of patient 1 . Note thymic hypoplasia.

might represent a novel multiple congenital anomalies/mental retardation (MCA/MR) syndrome involving an early embryonic defect of the neural crest and mesectodermal derivatives of the third and fourth pharyngeal pouches.

\section{Case reports}

Inclusion criteria for DGS were the presence of at least three of the major features: (1) thymic hypoplasia or aplasia, (2) hypocalcaemia or hypoplasia of the parathyroids or both, (3) conotruncal cardiac malformation, and (4) dysmorphic features including short palpebral fissures, broad nasal bridge, small mouth, small, low set ears, and micrognathia. Inclusion criteria for the CHARGE association were at coloboma, choanal atresia retardation of physical and mental development or cerebral anomaly, genital hypoplasia in males, and ear anomalies/deafness. Velopharyngeal insufficiency, dysmorphic features (square face, shallow orbital ridges), and cranial nerve palsy were considered accessory criteria. ${ }^{22}$

PATIENT 1

Patient 1 was a boy born at term with full blown DGS including tetralogy of Fallot with atrial septal defect, thymic hypoplasia (fig 1) confirmed at necropsy, hypocalcaemia (1.67 $\mathrm{mmol} / 1$, normal range $2.2-2.6 \mathrm{mmol} / \mathrm{l}$ ), a broad nasal bridge, and microretrognathia. $T$ cell lymphocyte count was normal. He also had features of the CHARGE association including unilateral retinal coloboma, partial choanal atresia, small and low set ears with an absent lobe, square face, and severe feeding difficulties with poor sucking and velopharyngeal insufficiency. Other features included right renal agenesis, syndactyly of the second and third fingers, malposition of the toes, and agenesis of the 12 th ribs. He died at 17 days of age. 


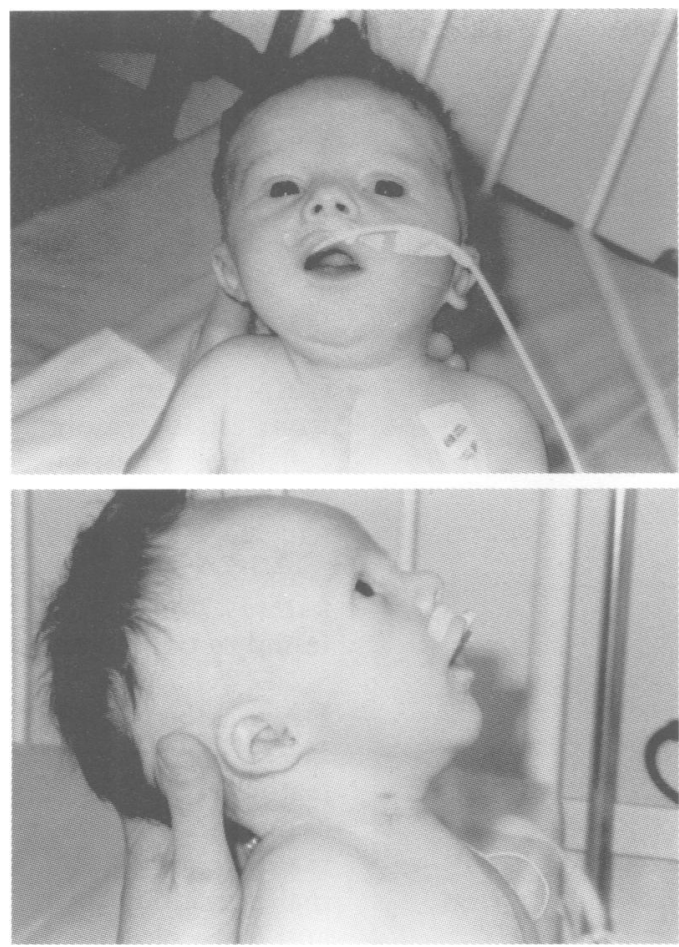

Figure 2 Patient 2. (A) Face: note the broad nasal bridge, small mouth, and facial asymmetry. (B) Profile: note small, dysplastic ear and micrognathia.

PATIENT 2

Patient 2 was a boy born at term with DGS, including truncus arteriosus and ventricular septal defect, thymic hypoplasia confirmed during cardiac surgery, hypocalcaemia (1.39 $\mathrm{mmol} / \mathrm{l}$ ), broad nasal bridge, and small mouth (fig 2A). He also had CHARGE association with left retinal coloboma, right choanal atresia, genital hypoplasia with micropenis, small, undescended testes, and reduced testo-

Table 1 Clinical features in five patients with both DGS and CHARGE association

\begin{tabular}{|c|c|c|c|c|c|}
\hline & \multicolumn{5}{|l|}{ Patients } \\
\hline & 1 & 2 & 3 & 4 & 5 \\
\hline Hypoplastic or absent thymus & + & + & + & + & + \\
\hline Hypocalcaemia & + & + & + & + & + \\
\hline Cardiac anomaly & $\begin{array}{l}\text { TOF + } \\
\text { ASD }\end{array}$ & $\begin{array}{l}\text { TAC + } \\
\text { VSD }\end{array}$ & - & BA & HA \\
\hline Retinal coloboma & + & + & + & + & + \\
\hline Choanal atresia & + & + & + & - & - \\
\hline Growth retardation & - & + & + & + & - \\
\hline Mental retardation & + & + & + & + & + \\
\hline Genital anomaly & - & + & - & + & - \\
\hline Deafness & ND & + & + & + & ND \\
\hline Velopharyngeal insufficiency & + & + & + & + & + \\
\hline Renal anomaly & + & - & + & - & - \\
\hline Distal limb abnormalities & + & + & - & + & - \\
\hline
\end{tabular}

TOF: tetralogy of Fallot, ASD: atrial septal defect; TA: truncus arteriosus, VSD: ventricular septal defect, BA: bicuspid aorta, HA: hypoplastic aortic arch, ND: not determined.

Table 2 Parameters of the five children at birth

\begin{tabular}{llllll}
\hline & \multicolumn{2}{l}{ Patient } & & & \\
\cline { 2 - 6 } & 1 & 2 & 3 & 4 & 5 \\
\hline Sex & Male & Male & Female & Male & Female \\
Gestation & Term & Term & 37 wk & Term & 33 wk \\
Birth weight $(\mathrm{g})$ & 2820 & 3820 & 2600 & 3410 & 1680 \\
Birth length $(\mathrm{cm})$ & $\mathbf{4 8}$ & 51 & 46 & 51 & 41 \\
Birth OFC $(\mathrm{cm})$ & 34 & 34 & 33.5 & 38 & 31 \\
Father's age $(\mathrm{y})$ & $\mathbf{4 2}$ & 36 & 22 & 26 & 30 \\
Mother's age $(\mathrm{y})$ & 35 & 30 & 29 & 30 & 34 \\
Consanguinity & - & - & - & - & - \\
Positive family history & - & - & - & - & - \\
\hline
\end{tabular}

sterone $(0.08 \mathrm{ng} / \mathrm{ml}$, normal range $1-2 \mathrm{ng} / \mathrm{ml})$. The ears were small, low set, and asymmetrical with an absent lobe (fig $2 \mathrm{~B}$ ) and deafness confirmed by auditory evoked potentials. Unilateral facial nerve palsy and micrognathia were also observed. Additional features were a posterior cleft palate, proximally set thumbs, and malposition of the toes. Cardiac repair was performed at the age of 1 month, followed by gastrostomy. At the age of 19 months, length and weight were -2 SD and head circumference $-1.5 \mathrm{SD}$. He had retarded psychomotor development and cerebral CT scan showed cortical atrophy.

\section{PATIENT 3}

Patient 3 was a girl with DGS, including facial dysmorphism with a broad nasal bridge, short palpebral fissures (fig 3A), hypocalcaemia shown by seizures on the first day of life (1.38 $\mathrm{mmol} / \mathrm{l}$ ) with very low plasma parathyroid hormone $(2.2 \mathrm{pg} / \mathrm{ml}$, normal range $10-65 \mathrm{pg} / \mathrm{ml})$, and thymic agenesis (fig $3 \mathrm{C}$ ) confirmed by mediastinal ultrasound. Cardiac ultrasound was normal. CHARGE association was also diagnosed with unilateral retinal coloboma, bilateral choanal atresia, and bilateral deafness confirmed by auditory evoked potentials. In addition, she had a square face, shallow orbital ridges, small, low set, and posteriorly angulated ears, velopharyngeal insufficiency, and a hypoplastic right kidney (fig 3B). Owing to severe feeding and respiratory problems, the patient underwent tracheostomy at 1 month of age. At the age of 4 months there was severe developmental delay.

\section{PATIENT 4}

Patient 4 was a boy born at term by caesarean section because of acute fetal distress. He had DGS with thymic agenesis confirmed by mediastinal ultrasound, profoundly decreased $T$ lymphocytes (total white blood cells $5000 / \mathrm{ml}$, T lymphocytes $0 \%$, normal range $6000-7200 /$ $\mathrm{ml}$ ), hypocalcaemia on the first day of life (1.5 $\mathrm{mmol} / \mathrm{l}$ ) with low plasma parathyroid hormone $(14.6 \mathrm{pg} / \mathrm{ml})$, bicuspid aorta, and retrooesophageal left subclavian artery. He also had CHARGE association with right retinal coloboma, square face, malformed, low set ears, shallow orbital ridges (fig 4A, B), micropenis, and bilateral deafness confirmed by auditory evoked potentials. Additional features were left duplicated thumb and micrognathia. Velopharyngeal insufficiency and gastro-oesophageal reflux required tracheostomy with gastrostomy and Nissen procedure. At the age of 6 months, he had postnatal growth deficiency (both height and weight $-4 \mathrm{SD}$ ).

\section{PATIENT 5}

Patient 5 was a girl born at 33 weeks of gestation by caesarean section because of retroplacental haematoma. DGS was diagnosed with hypoplastic aortic arch and ventricular septal defect, congenital hypocalcaemia $(1.6 \mathrm{mmol} / \mathrm{l})$, decreased $T$ lymphocytes without thymic hypoplasia (total white blood cells $14000 / \mathrm{ml}$, lymphocytes $1200 / \mathrm{ml}$ ), and short palpebral fissures. CHARGE association was also 

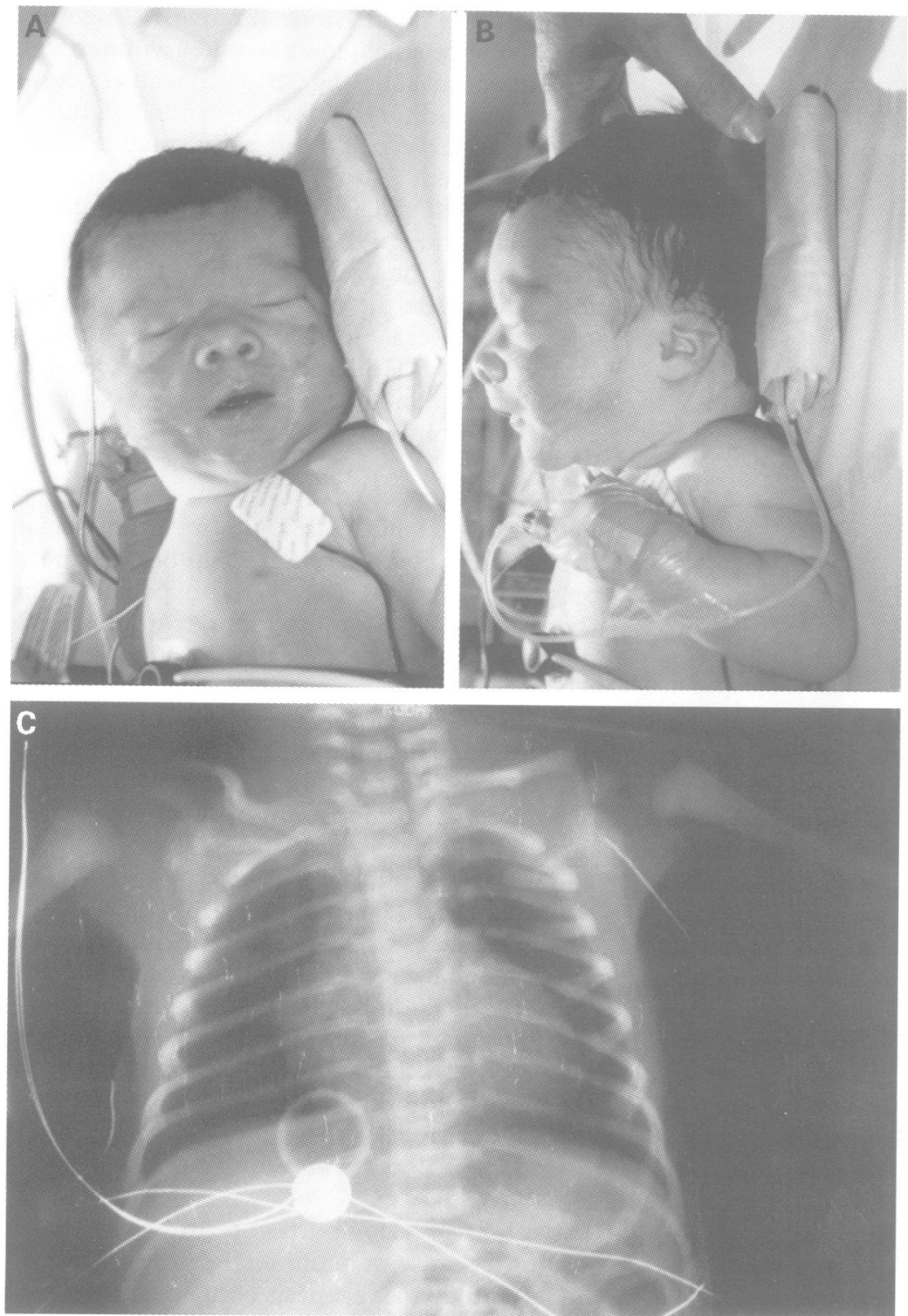

Figure 3 Patient 3. (A) Face: note broad nasal bridge, short palpebral fissures, square face, and shallow orbital ridges. (B) Profile: note small, square ear. (C) Thoracic $x$ ray: note
absent thymus.
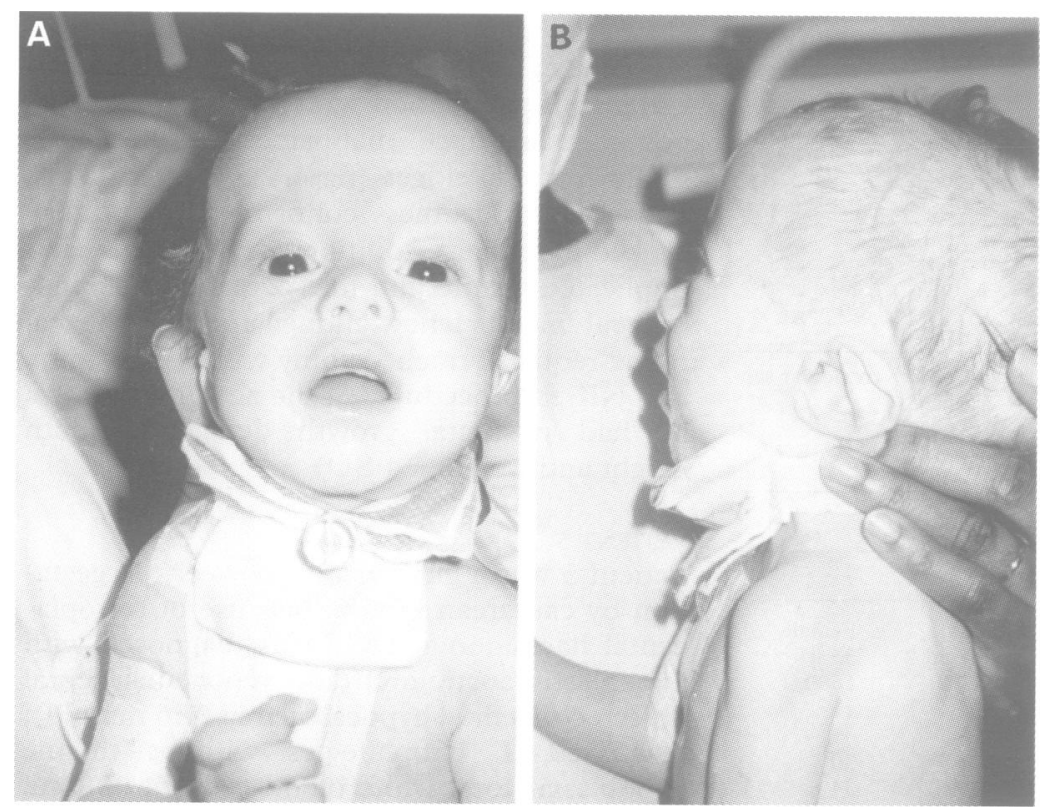

Figure 4 Patient 4. (A) Face: note square face and shallow orbital ridges. (B) Profile: note severely dysplastic ear. considered with the finding of bilateral retinal coloboma and severely dysplastic ears. She had no choanal atresia but velopharyngeal insufficiency and hydrocephalus. She died on day 13 with sepsis and hepatic abscess.

\section{Chromosomal investigations}

No abnormality was observed in any of the five children using $\mathrm{RGH}$ banding karyotyping. Fluorescence in situ hybridisation (FISH) was performed on at least 20 metaphase spreads from blood lymphocytes and lymphoblastoid cells lines. Probes used for FISH were cosmid clones SC11.1 and 48F8, encompassing a 2 $\mathrm{Mb}$ DNA fragment in the DGS critical region. ${ }^{23}{ }^{24}$ In each of the five patients and their parents, the SC11.1 and $48 \mathrm{~F} 8$ probes were found to be not deleted.

\section{Discussion}

Here we report on five patients presenting with features of both DGS and CHARGE association. All patients had at least three of the major features of DGS: conotruncal cardiac malformation, thymic hypoplasia or aplasia, and hypocalcaemia (table 1). In addition, two patients were severely immunodeficient. $\mathrm{Pa}$ tient 3 had some dysmorphic features of DGS, namely broad nasal bridge and short palpebral fissures. None of the five patients had a $22 \mathrm{q} 11.2$ deletion which is found in more than $90 \%$ of cases with DGS. ${ }^{8-13}$ In addition, each of them had malformations usually found in the CHARGE association, namely coloboma (5/ 5), choanal atresia (3/5), hypogonadism with micropenis ( $2 / 3$ boys), deafness (3/3), severe velopharyngeal insufficiency (5/5), and facial palsy (1/5).

Both DGS and CHARGE association have been ascribed to a developmental defect involving structures derived from the third and fourth pharyngeal pouches. ${ }^{25}$ In addition, facial anomalies and neonatal brain stem dysfunction have been attributed to a deficiency of neural crest cells derived from the first branchial arch. ${ }^{26}$ While only $10 \%$ of patients with DGS lack a 22q11.2 deletion, several other chromosomal anomalies have been reported in DGS, in particular monosomy $10 \mathrm{p} 13^{2728}$ and $17 \mathrm{p} 13 .^{29}$ These data strongly support genetic heterogeneity of DGS. Moreover, DGS phenocopies have been observed in diabetic, alcoholic, and retinoid embryopathies. ${ }^{30-33}$ In contrast, the origin of CHARGE association remains unknown. The vast majority of cases are sporadic. However, the existence of several familial cases, increased paternal age at birth of the patients, ${ }^{34}$ and concordance in monozygotic twins have been reported, indicating that genetic factors are likely to contribute to CHARGE association. ${ }^{14} 181935$ In support of this, a small number of cytogenetic abnormalities have been observed in CHARGE patients including partial trisomy $18,{ }^{15}$ unbalanced $2 ; 18$ and $3 ; 22$ translocations, ${ }^{20}$ duplication of $1 \mathrm{q}^{36}$ trisomy $8 \mathrm{q}^{37}$ and balanced $6 ; 8$ translocation. ${ }^{21}$

Thus, the patients reported here may represent a novel disorder or, alternatively, the variable expression of either DGS or CHARGE association. Both syndromes do have a broad 
phenotypic spectrum. However, while cleft palate or limb anomalies have been described in DGS, coloboma and choanal atresia are very rare findings in DGS or 22q11.2 deletion phenotypes. ${ }^{238-42}$ Moreover, FISH analysis excluded a 22q11.2 deletion in our patients. Alternatively, the genetic defect in our patients could involve another chromosomal region. However, neither deletion of $10 \mathrm{p}$ nor any other chromosomal anomaly was found in the five patients reported here. These patients could also be considered to have CHARGE association. The phenotypic spectrum of CHARGE association is broad ${ }^{15-17}$ and some of the rare features of CHARGE were observed in our series, namely limb anomalies (3/5), renal malformation (2/5), and cleft palate (1/5). Finally, these patients might be affected with an as yet undescribed MCA/MR syndrome. In fact, DGS patients with features of CHARGE association have already been reported, suggesting a consistent congenital birth defect. $^{14}{ }^{43-45}$ Whatever the cause of this syndrome, the absence of a family history in each of the five cases and the increased paternal age in two cases (table 2) favour the role of a de novo mutation or a subtle infracytogenetic chromosomal anomaly. In addition, we cannot exclude the possibility of genetic heterogeneity or phenocopies, and mutation screening should be undertaken in these patients once the molecular bases of DGS and CHARGE association are characterised. Finally, as far as prognosis is concerned, this new MCA/MR syndrome seems closer to CHARGE association than DGS, in particular with respect to severe feeding and respiratory problems. Two patients died during the first months of life and both neurological and psychomotor development were severly impaired in each of the survivors.

We thank Alan Strickland for his help in preparing this We thank Alan Strickland for his help in preparing this
manuscript and Didier Theophile (Paris) for helpful discussions.

1 Lischner HW. DiGeorge syndrome(s), f Pediatr 1972;81:1042-4.

2 Conley ME, Beckwith JB, Mancer JFK, Tenckhoff L. The spectrum of the DiGeorge syndrome. $\mathcal{F}$ Pediatr 1979;94: 833-90.

3 Mueller W, Peter HH, Wilken M. The DiGeorge syndrome: clinical evaluation and course of partial and complete clinical evaluation and course of partial and complet

4 Carey JC. Spectrum of the DiGeorge "syndrome". 7 Pediatr Carey JC. Spect

5 Wilson DI, Burn J, Scambler P, Goodship J. DiGeorge syndrome: part of CATCH 22. f Med Genet 1993;30:8526.

6 Greenberg F. DiGeorge syndrome: an historical review of clinical and cytogenetic features. F Med Genet 1993;30:803 6

7 Hall JG. CATCH 22. $₹$ Med Genet 1993;30:801-2.

8 De la Chapelle A, Herva R, Koivisto M, Aula P. A deletion in chromosome 22 can cause DiGeorge syndrome. Hum Genet 1981;57:253-6.

9 Carey AH, Kelly D, Halford S. Molecular genetic study of the frequency of monosomy 22q11 in DiGeorge syndrome. Am F Hum Genet 1992;51:964-70.

10 Scambler PJ, Carey AH, Wyse RKH, et al. Microdeletions within 22q11 associated with sporadic and familial DiGeorge syndrome. Genomics 1991;10:201-6.

11 Driscoll DA, Salvin J, Sellinger B, et al. Prevalence of 22q11 microdeletions in DiGeorge and velocardiofacial syndromes: implications for genetic counselling and prenatal diagnosis. F Med Genet 1993;30:813-17.

12 Wiliagnosis. F Med Genet 1993;30:813-17. Monosomy 22q11. Arch Dis Child 1993;86:187-9.

13 Demczuk S, Aurias A. DiGeorge syndrome and related syndromes associated with $22 \mathrm{q} 112$ deletions. Ann Genet 1995;38:59-76.
14 Pagon RA, Graham JM, Zonana J, Young SL. Coloboma, agon RA, Graham JM, Zonan $J$, Young atresia with multiple congenital heart disease, and choanal atresia with multiple

15 Davenport SLH, Hefner MA, Mitchell JA. The spectrum of clinical features in CHARGE syndrome. Clin Genet 1986;29:298-310.

16 Oley CA, Baraitser M, Grant DB. A reappraisal of the CHARGE association. F Med Genet 1988;25:147-56.

17 Blake KD, Russell-Eggitt IM, Morgan DW, Ratcliffe JM, Wyse RKH. Who's in CHARGE? Multidisciplinary management of patients with CHARGE association. Arch Dis Child 1990;65:217-23.

18 Ho CK, Kaufmann RL, Podos SM. Ocular colobomata cardiac defect, and other anomalies: a study of seven case including two sibs. F Med Genet 1975;12:289-93.

19 Hittner HM, Hirsch NJ, Kreh GM, Rudolph AJ. Colobomatous microphthalmia, heart disease, hearing loss, and mental retardation - a syndrome. $\mathcal{F}$ Pediatr Ophthal Strabismus 1979;16:122-8.

20 Clementi M, Tenconi R, Turolla L, Silvan C, Bortotto L, Artifoni L. Apparent CHARGE association and chromosome anomaly: chance or contiguous gene syndrome. $A m \mathcal{F}$ Med Genet 1991;41:246-50.

21 Hurst JA, Meinecke P, Baraitser M. Balanced $t(6 ; 8)(6 \mathrm{p} 8 \mathrm{p}$; $6 \mathrm{q} 8 \mathrm{q})$ and the CHARGE association. If Med Genet 1991;28:54-5.

22 Lacombe D, Sarlangue J. Association CHARGE: paralysie ou asymétrie faciale? Pediatrie 1990;45:625.

23 Desmaze C, Prieur M, Amblard F, et al. Physical mapping by FISH of the DiGeorge critical region (DGCR): involvement of the region in familial cases. Am F Hum Genet 1993; 53:1239-49.

24 Halford S, Wadey R, Roberts C, et al. Isolation of a putative transcriptional regulator from the region of $22 \mathrm{q} 11$ deleted in DiGeorge syndrome, Shprintzen syndrome and familial in DiGeorge syndrome, Shprintzen syndrome and familial 107 .

25 Lammer EJ, Opitz JM. The DiGeorge anomaly as a developmental field defect. Am $\mathcal{f}$ Med Genet (Suppl) 1986; 2:113-27

26 Le Douarin N. Migration and differentiation of neural crest cells. Curr Top Dev Biol 1980;16:31-85.

27 Greenberg F, Elder FFB, Haffner P, Northrup H, Ledbetter D. Cytogenetic findings in a prospective series of patients with DiGeorge anomaly. Am $\mathcal{F}$ Hum Genet 1988;434:60511.

28 Daw SCM, Taylor C, Kraman M, et al. A common region of $10 \mathrm{p}$ deleted in DiGeorge and velocardiofacial syndromes. Nat Genet 1996;13:458-60.

29 Greenberg F, Courtney KB, Wessels RA. Prenatal diagnosis of deletion $17 \mathrm{p} 13$ associated with DiGeorge anomaly. $A m \mathcal{F}$ Med Genet 1988;31:1-4.

30 Davis LA, Sadler TW. Effects of vitamin A on endocardial cushion development in the mouse heart. Teratology 1981;24:139-48.

31 Johnston MC, Sulik KK, Webster WS, Jarvis BL. Isotretinoin embryopathy in a mouse model: cranial neural crest involvement. Teratology 1985;31:26A.

32 Poswillo D. The pathogenesis of the Treacher Collins syndrome (mandibulofacial dysostosis). Br $\mathcal{F}$ Oral Surg 1975;3:1-26.

33 Sulik KK, Johnston MC, Daft PA, Russell WE, Dehart DB. Fetal alcohol syndrome and DiGeorge anomaly. $A m \mathcal{F} \mathrm{Med}$ Genet 1986;2:97-112.

34 Tellier AL, Lyonnet S, Cormier-Daire V, et al. Increased paternal age in CHARGE association. Clin Genet 1996;50: 548-50.

35 Levin DL, Muster AJ, Newfeld EA, Paul MH. Concordant aortic arch anomalies in monozygotic twins. $f$ Pediatr 1973; 83:459-61.

36 Dev VG, Butler MG, Philips JA. 1q duplication due to unequal crossover in a patient with CHARGE association and Di George sequence. Am f Hum Genet 1985;37:90A.

37 Townes PL, White MR. Inherited partial trisomy 8q (22-qter). Am f Dis Child 1978;132:498-501.

38 Huff DS, Lischner HW. Congenital malformations associated with DiGeorge syndrome. Am f Pathol 1973;71:6.

39 Cleveland WW, Fogel BD, Brown WT, Kay HEM. Foetal thymic transplant in a case of DiGeorge's syndrome. Lancet 1968;ii: 1211.

40 Pabst HF, Wright WC, LeRiche J, Stiehm ER. Partial DiGeorge with substantial cell-mediated immunity. $\mathrm{Am} \mathcal{F}$ Dis Child 1976;130:316.

41 Cormier-Daire V, Iserin L, Théophile D, et al. Upper limb malformations in DiGeorge syndrome. Am 7 Med Genet 1995;56:39-41.

42 Ryan AK, Goodship JA, Wilson DI, et al. Spectrum of clinical features associated with interstitial chromosome 22q11 deletions: a European collaborative study. $\mathcal{F}$ Med Genet 1997;34:798-804.

43 Siebert JR, Graham JM, McDonald C. Pathologic features of the CHARGE association: support for involvement of the neural crest. Teratology 1985;31:331-6.

44 Klein VR. Choanal atresia and associated anomalies. In: Proceeding of the Greenwood Genetic Center. Clinton: Jacobs Press, 1987:213.

45 Brown OE. Bilateral posterior choanal atresia: a morphological and histologic study, and computed tomographic correlation. Int $\mathcal{F}$ Pediatr Otorhinolaryngol 1987;13:125-42. 